\title{
OBSTRUCTIONS TO JOB SATISFACTION: VOICES OF SMALL TO MEDIUM ENTERPRISE EMPLOYEES IN THE MANUFACTURING INDUSTRY IN ZIMBABWE
}

\author{
Takupiwa Nyanga \\ Julius Nyerere School of Social Sciences, Great Zimbabwe University, Masvingo, Zimbabwe \\ Email: takupiwa@gmail.com \\ Rosemary Sibanda \\ University of KwaZulu- Natal, Durban, South Africa \\ Email: rosemary.sibanda@gmail.com \\ Jan Kruger \\ School of Business Leadership, University of South Africa, Pretoria, South Africa \\ Email: jkruger2000@yahoo.com
}

\begin{abstract}
The purpose of this study was to investigate job satisfaction problems faced by employees in Manufacturing Small to Medium Enterprises (MSMEs). A qualitative research methodology was utilized to carry out the study. Interviews were conducted on 50 participants who were selected from MSMEs in Masvingo urban. Thematic data analysis method was employed to analyze data. The study established that job satisfaction among MSMEs employees was extremely low and needed to be addressed as prompt as possible so as to reduce its negative ramifications to MSMEs. MSMEs' poor financial performance, operating in distressed economic environment, failure by management to develop strategies of propelling employee satisfaction, unitary approach to labor relations, social problems, failure to develop a safe and secure work environment were some of the impediments to job satisfaction. The study concluded that job satisfaction challenges are some of the key issues that need to be addressed since they directly affect organizational performance and growth.
\end{abstract}

Keywords: Job satisfaction, Manufacturing Small to Medium Enterprises, Employee, Impediments.

\section{INTRODUCTION}

The Zimbabwean economy has been in a downward spiral for over two decades. Most organizations in Zimbabwe faced a host of operational challenges because of the persisting economic distress. The 2000 to 2008 economic distress in Zimbabwe resulted in most well established manufacturing firms in Masvingo urban either closing or downsizing their operations. While the closure of established firms was not a 


\section{Nyanga T. \\ OBSTRUCTIONS TO JOB SATISFACTION: VOICES OF SMALL TO MEDIUM ENTERPRISE EMPLOYEES IN THE MANUFACTURING INDUSTRY IN ZIMBABWE}

welcome development it, however created an opportunity for the incubation of Manufacturing Small to Medium enterprises (MSMEs). The closure or reduction of operations by large manufacturing firms ignited the government and other development agencies to increase their efforts on the incubation, promotion, support and development of MSMEs with the view of resuscitating and growing the economy (Maseko and Manyanis 2011). The government and other development agencies assisted most university and technical college graduates to establish light engineering and food processing manufacturing companies. There is a proliferation of MSMEs in Masvingo urban which manufacture building materials, textile products, wood products and detergents. MSMEs constitutes the most viable and veritable vehicles for the revival of the manufacturing sector and the economy in general. MSMEs contribute significantly to the country's Gross Domestic Product (GDP), employment creation, poverty reduction, socio-economic and infrastructural development in the country.

Development agencies in Zimbabwe and beyond render financial and material support to MSMEs, but they leave out critical performance success factors such as job satisfaction and motivation of workers. The Zimbabwe SMEs Association (2013) annual report indicated that MSMEs have become a major source of employment in Zimbabwe and employ more than $50 \%$ of the workforce in the country. Despite it being the main source of employment and receiving unprecedented support, MSMEs have however registered the lowest level of employee satisfaction and as a result they have failed to grow and survive in a competitive business environment. A survey conducted by Gombarume \& Mavhundutse (2014) showed that $67 \%$ of employees in the manufacturing sector were either somewhat or totally unsatisfied with their jobs. In Masvingo urban between $48 \%$ and $76 \%$ of workers in MSMEs wanted to quit their jobs (Nyanga et al 2013). With all these discontented employees, one would assume that there have to be challenges that drive these high percentages. It is these challenges which this study aims to unravel, an area which has not been explored by many researchers. The study also investigates the reactions or responses from employees with low job satisfaction and how they act on the job. It is critically essential to understand how workers react when they are not satisfied with their work. Understanding job satisfaction challenges, problems and tribulations help organizations to address discontent among workers.

\section{LITERATURE REVIEW}

Job satisfaction is the extent to which workers like (satisfaction) or dislike (dissatisfaction) their jobs (Nyanga 2018, Nyanga and Sibanda 2019). It is the degree to which an employee views his/her job as valuable or invaluable or good or bad. It is a perception an employee develops about his/her job which result in him/her liking or disliking the job. On the other hand Lee-Kelley et al (2007) viewed job satisfaction as an employee's attitudes of overall acceptance, contentment, and 
enjoyment in his/her work. Employee satisfaction is influenced by job characteristics, relationships and the work environment. For purpose of this study job satisfaction is defined as a feeling of contentment, fulfillment or enjoyment an employee derives from the facets of his/her job such as work environment, nature of supervision, culture of the organization, structure of the organization and intrinsic factors.

A study by Akehurst et al (2009) established that job satisfaction and commitment to the team are key aspects that directly and positively influence on organizational entrepreneurship. Milenkovic (2019) further clarified the importance of job satisfaction when he argued that job satisfaction keep employees happy and all types of businesses healthy. Job satisfaction can be spiked by the employer demonstrating that he/she truly cares for his/her workers by heftily rewarding hard work, commitment, loyalty and dedication to duty. SMEs should make employee wellness and engagement a priority. Such a gesture raises employees' self-esteem and job satisfaction. Manzoor et al (2019) say leadership style is an essential factor in organizational performance and employee happiness. SMEs that employ the appropriate leadership style are bound to have highly motivated and satisfied employees. Sugandini, et al (2018) also reiterated that job satisfaction is one of the major precipitators of employee engagement. Several studies (Beaver \& Boss 2002, Gombarume and Mavhndutse 2014) concurred that it has not been easy for researchers and academics to reach a consensus on the definition of SMEs. The complexity and difficulty in reaching a consensus by authors regarding the definition of MMEs has resulted in authors defining it differently using divergent perspectives. Some authors based their definition on the number of employees while others based their definition on turnover. The definitions basically differ from country to country, or sector to sector. Some scholars define SMEs in terms of employment, turnover and asset base. For purposes of this study, Small Enterprises Development Corporation (SEDCO) (2010) definition of SME is going to be used. SEDCO (2010) defined SMEs as a firm that employ's less than hundred employees and has a maximum annual sales turnover of US $\$ 830$ 
antecedents to organizational development and paid very little if any attention to job satisfaction challenges yet job satisfaction challenges faced by MSMEs have caused a serious damage to upcoming manufacturing firms. Nyanga et al (2012) observed that depending on other factors of organizational performance while ignoring human resource management issues such as job satisfaction may not help firms realize their goals. Job satisfaction is vital importance to productivity and growth of organizations (Nyanga et al 2012, Shamuni, et al 2015). The discontent of employees in various organizations is a sign of tribulations that impede job satisfaction.

Employees are the principal and primary assets of MSMEs. Without competent, skilled and satisfied workers, most MSMEs would find it extremely difficult, if not impossible to realize set goals (Bates 2004, Zindiye 2012, Tinarwo 2016). Job satisfaction in MSMEs has become an issue of accelerating concern because of its big influence on productivity, growth and survival of firms. Studies (Fu \& Deshpande 2014, May-Chiun \& Ramayah 2011, Tinarwo 2016) have shown that organization with satisfied employees increase their market share and stand better chances to achieve their set goals. Organizations with content labor produce quality products and treat customers as 'kings', which are key components to the building of a strong market base and customer loyalty. Satisfied employees also help the firm to wither the storm of operating in a volatile, complex, ambiguous and uncertain business environment such as the one prevailing in Zimbabwe. Job satisfaction is therefore an important human resource management agenda and objective since it has the potential of either "making or breaking" an organization.

Low job satisfaction results in psychological withdrawal (Nyanga et al 2018), growing production costs, low customer satisfaction and reduction in profit and productivity. MSMEs in Zimbabwe experience a host of challenges which have resulted in the majority of them failing to survive the economic upheavals and fast growing technological changes (Chinomona et al 2014). Concentrating on job satisfaction therefore makes a lot of business sense since it helps shape the behavior, attitude, satisfaction and motivation of workers. Job satisfaction is vital especially in MSMEs because in today's business firms are expected to possess knowledge, technological proficiency, competitiveness, profitability and productivity (Tinarwo 2016, Gombarume \& Mavhundutse 2014). Due to low job satisfaction most MSMEs' performance slowed down and the relations between employers and employees have been strained. Low job satisfaction results in workers exhibiting behaviour that is against the norms, expectations and values of the organisations. Low job satisfaction impedes organisational performance, increases the rate of accidents, absenteeism and labour turnover (Nyanga \& Sibanda 2019).

Low job satisfaction among MSMEs has resulted in several SMEs that were established in Zimbabwe failing to survive the harsh economic challenges prevailing in the country and the stiff competition by established manufacturing firms. Most SMEs experienced high rate of labour turnover with 
manufacturing SMEs registering the highest number due to low job satisfaction. The high rate of labour turnover has resulted in most MSMEs in Zimbabwe failing to take off, survive and grow (Tinarwo 2016). Only a few manufacturing companies that were established since independence have managed to grow and become large corporations. Most MSMEs were left operating with inexperienced and in some cases semi-skilled employees (Moyo 2012). SMEs including those in the manufacturing sector access low interest loans from SEDCO to capitalize and re-capitalize their businesses (SEDCO 2010) but they still fail to grow and become competitive because of low morale and satisfaction among workers. In December 2016 the rate of labour turnover and absenteeism in MSMEs in Zimbabwe was pegged at 0.58 and 0.47 per annum respectively. Job satisfaction influences employee commitment, motivation and loyalty to the organisation. Shamuni et al (2015) argue that the dynamic business environment require highly skilled employees to increase enterprises competitive edge, growth, survival and profitability. Literature search shows that several studies have been done on job satisfaction, but no study investigated the job satisfaction challenges faced by MSMEs in a developing country. Literature search has shown that most employees in MSMEs have over the years not been pleased with their work. It is therefore prudent to investigate the challenges and impediments to their job satisfaction.

\section{METHODOLOGY}

This study employed a qualitative research approach. Two essential types of data were gathered for the study; primary and secondary. Primary data was collected using face-to face semi-structured interviews from fifty (50) fulltime and part-time workers of MSMEs. Participants comprised of directors, chief executive officers, senior and middle level managers and employees at functional levels from various manufacturing organizations. The list of MSMEs and actual population of the study was difficult to establish because there is no MSME urgency which has a data base for MSME in Masvingo city. To get participating organizations three MSMEs were initially identified and the rest were recommended by the initially identified organizations. Participants were thus sampled using snowball sampling method. An initial group of participants was found and then they helped in the recruitment of the other participants. Permission to do the study was sought from CEOs or persons in charge of MSMEs. The non-random sampling where respondents were specifically targeted gave the researcher an opportunity to get full and maximum comprehension of issues under investigation. Secondary data was accessed from journals, internet and library, annual, monthly or weekly reports. Secondary data was based on previous findings of other researchers and academics and organizations' archival reports. Thematic data analysis was used to analyze the gathered data. Data was grouped into distinct categories and then themes were developed. Data was coded and slotted into categories. Coding data gave the researcher an 
OBSTRUCTIONS TO JOB SATISFACTION: VOICES OF SMALL TO MEDIUM ENTERPRISE EMPLOYEES IN THE MANUFACTURING INDUSTRY IN ZIMBABWE

opportunity to develop themes and also identify other issues that emerged which were not necessarily covered by the interview guide.

\section{RESULTS}

\subsection{Biographical Data}

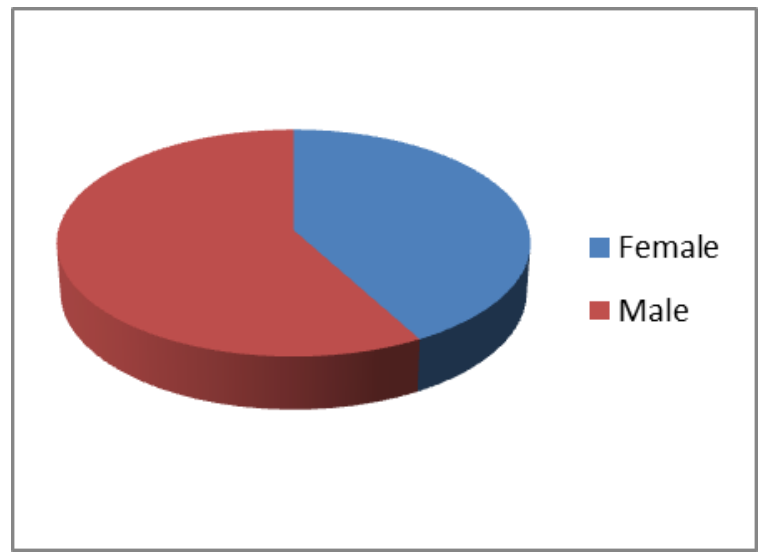

FIGURE 1. PARTICIPANTS BY GENDER

Source: Created by author

The chart shows that there are more male than female employees in MSMEs in Masvingo Urban. Results also show that a significant number of female employees entered into the formerly male dominated industries such as manufacturing of building materials, detergents and other goods. In MSMEs tasks and duties are assigned to employees without taking into consideration one's gender.

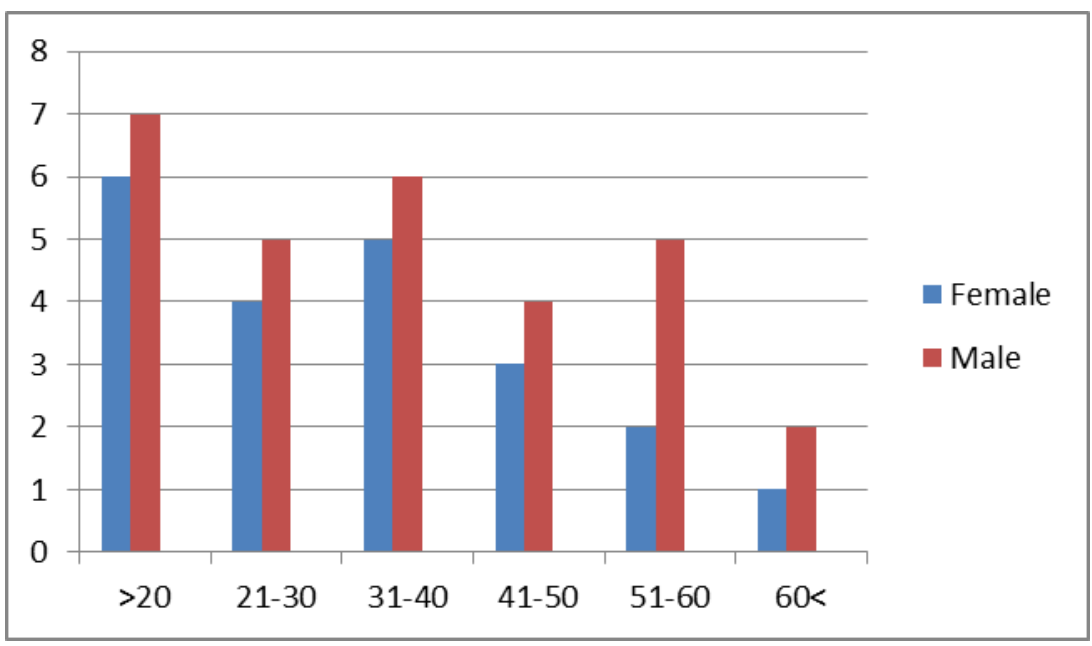

FIGURE 2. AGE OF PARTICIPANTS 
Nyanga T.

OBSTRUCTIONS TO JOB SATISFACTION: VOICES OF SMALL TO MEDIUM ENTERPRISE EMPLOYEES IN THE MANUFACTURING INDUSTRY IN ZIMBABWE

Source: Created by author

The bar graph shows that MSMEs are dominated by employees whose age ranges from 20 - 40 years. The 20-40 age groups are an age category comprising of people with a host of social, economic and technological needs. Chen \& Silverthorne (2008) observed that the most difficult age group to satisfy is the 18-45. Probably this explains why there is extremely low job satisfaction among employees in MSMEs in Masvingo urban since it is dominated by that age group.

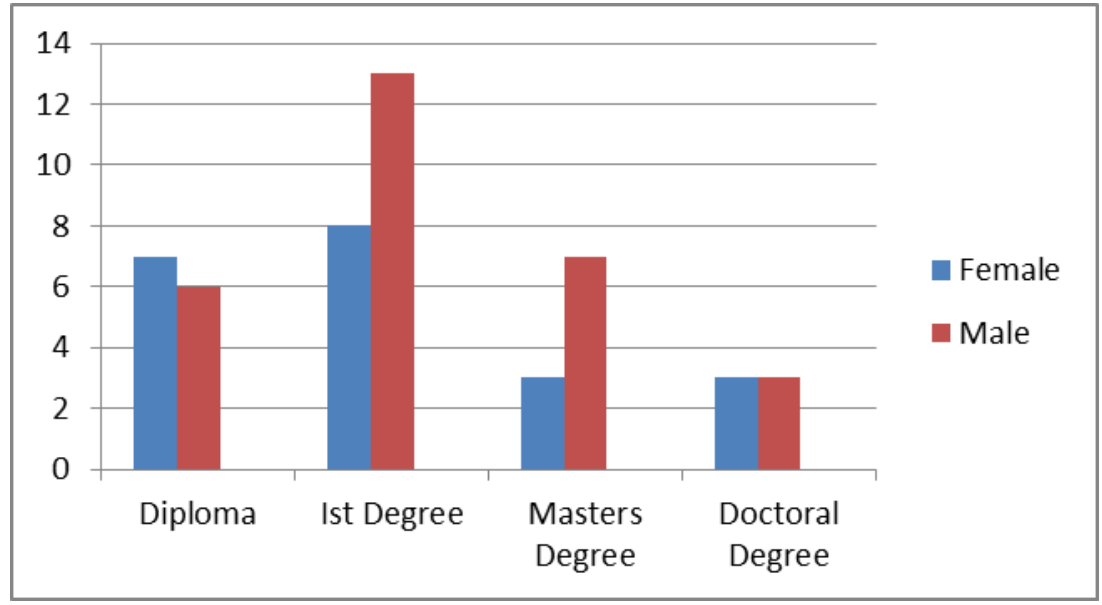

FIGURE 3. PARTICIPANTS' EDUCATIONAL QUALIFICATIONS

Source: Created by author

All the participants attained tertiary education qualifications. Of importance to note is that the majority of them attained a degree which is essential in the production of quality and most sought after products, marketing and maintaining a good market share. Most participants with masters and doctoral degrees were managers and managing directors of MSMEs. It implies that most firms were led by competent and highly educated people with adequate knowledge on leadership, management of finances, marketing and human capital management.

\subsection{Impediments to Job Satisfaction}

\section{Emerging themes and verbatim quotations from respondents}

Almost all the respondents indicated that the use of an 'unwelcome' leadership style significantly impedes job satisfaction. One of the respondents remarked, "MSMEs employ autocratic leadership style, which is not favorable to employee satisfaction because it does not accord workers room to share their experiences and views. Creativity is therefore stifled hence entrepreneurship and job satisfaction is 


\section{Nyanga T. \\ OBSTRUCTIONS TO JOB SATISFACTION: VOICES OF SMALL TO MEDIUM ENTERPRISE EMPLOYEES IN THE MANUFACTURING INDUSTRY IN ZIMBABWE}

reduced". Participant 18 said, "Employers use force or coercion us to do things the way they feel it should be done even if employees feel that it should be done in that manner. Employees are not comfortable with the approach of being directed to do things in particular manner, they prefer to be given autonomy to generate ideas on the best ways of performing specific tasks." Participant 27 reiterated, "Most MSMEs managers prefer using autocratic leadership style, yet it is one of the leadership styles which most MSME employees are not comfortable with."

The unavailability of financial resources to recapitalize the business and also to cover operational costs was viewed as one of the major impediments to job satisfaction among MSME workers. Below are some of the remarks made by the respondents Participant 42, "I have gone three months without receiving my salary, hence I no longer have motivation to continue working for this company. Delays in giving workers' salaries and wages seriously derail the employee satisfaction process in MSMEs." Participant 28 remarked, "Most MSMEs do not have adequate financial and material resources to fund their investment activities. The unavailability of adequate financial and material resources to run MSMEs results in the delays in disbursing workers' salaries and wages. A delay in the disbursement of salaries and wages reduces workers' job satisfaction. Participants further indicated that some MSMEs use two methods to determine an employees' wages. Some workers' wages, salaries and other benefits are based on the time worked while others are based on periodical assessment by the Managing Directors, Chief Executive Officers or their representatives. Such inconsistencies in the management of rewards derail job satisfaction.

47 out of 50 respondents indicated that most MSMEs face stiff competition from both the local and international corporations. Stiff competition results in the majority of MSMEs losing a significant amount of their market share and also exerting pressure on workers to produce the quality and quantity of goods which are beyond their capacity and capability. Participant 3 , "Our Company lost a lot of business to Chinese firms, hence they no longer have the capacity to give its workers living wages." Participant 11 said, "Our company experiences a lot of shortage of materials and stiff competition from both local and foreign organizations, which in turn negatively affect job satisfaction."

Almost the respondents indicated that most MSMEs operate in inappropriate physical infrastructures such as dilapidated buildings or deserted open spaces. Inappropriate work stations negatively affect employee satisfaction. One of the respondent remarked "We work in deplorable work stations with inadequate power supply, exposed power cables and inadequate workspace. Such environment exposes us to risks and in turn reduces our level of satisfaction. Given an opportunity I will look for a less risk job". Participant 23 said, "How can I develop a positive attitude towards my work yet I work in a dilapidated work station and expected to produce quality goods yet I use outdated tools." It shows that infrastructure and tools are key to job satisfaction. 


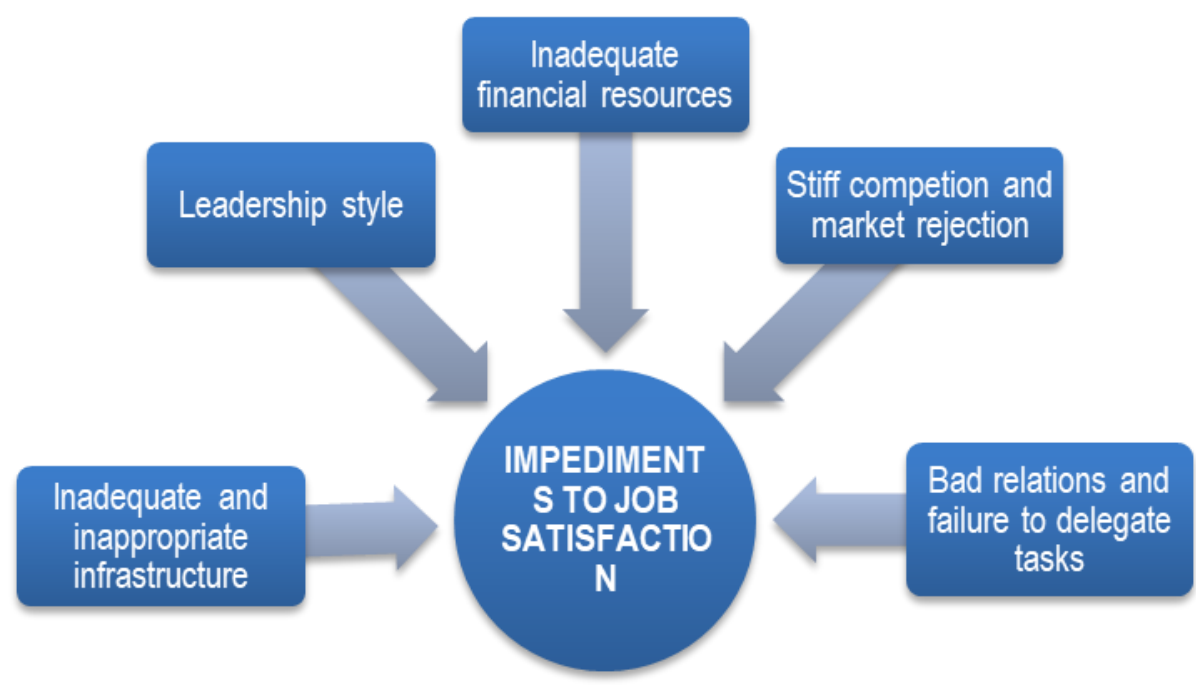

FIGURE 4. IMPEDIMENTS TO JOB SATISFACTION

Source: Created by author

\section{DISCUSSIONS}

The study revealed that whilst MSMEs receive financial and capacity building support from various stakeholders, they received very little if any support in the area of employee satisfaction and labor management in general. MSMEs workers experience extremely low job satisfaction mainly due to failure by management to prioritize human capital satisfaction. An increase in the rate of labor turnover, collective job actions, absenteeism and other misdemeanors among MSMEs workers are some of the indicators of low job satisfaction. The study further established that most MSMEs do not have workplace policies, rules and regulations to help management to consistently and fairly treat workers. The absence of the code of conduct and other rules and regulations has resulted in unfair treatment of employees, which bred disputes that costs the firm its corporate image and also its hard earned profit. The findings are in sync with Chinomona (2014) who argued that MSMEs, the world over are lagging behind in the development of workplace policies that promote employee satisfaction. The absence of clear and effective MSMEs policies, rules and regulations cripples the job satisfaction agenda of MSMEs employees and has yielded a negative impact on job satisfaction.

The study also established that leadership styles which are usually employed in MSMEs do not arouse employee satisfaction. Autocratic type of leadership is the most preferred form of leadership but it is regarded by most workers as stifling creativity, innovation and application of the knowledge workers acquired during their tertiary education studies. The outcome of the study buttressed earlier researches 
carried out by (Mosadegh \& Yamahammadian 2006, Chen 2005) who established that there is a strong positive correlation between leadership style and job satisfaction. Other forms of leadership styles such as transactional, transformational and democratic should be used in MSMEs so as to give firms the impetus to be competitive and in turn amass wealth that can be used to propel employee satisfaction. Transformational leadership affects the values, motivates subordinates, impart skills and competencies in workers, which are all key antecedents to employee satisfaction. Most leadership styles exhibited in MSMEs lack four key job satisfaction leadership devotions which are; communication, individual consideration, intellectual stimulation and charisma (Zindiye 2012, Moha et al 2007). Without the four leadership dimensions it is difficult to propel employee satisfaction. Most MSMEs do not provide their subordinates with full information which empower them to effectively and efficiently execute their duties. Individual needs are also not seriously considered yet they directly and indirectly influence job satisfaction. Social issues such as death or illness in the family also bear serious ramifications to the employee's level of satisfaction.

Job satisfaction among MSMEs is impeded by inadequate financial resources. Regardless of government and other development agencies financial and favorable policies support for MSMEs, most MSMEs continue to experience financial challenges. Financial instability has deterred manufacturing organizations from meeting their financial obligations to their workers. All the respondents indicated that most if not all MSMEs pegged their workers' wages and salaries way below the poverty datum line level. To make matters worse most MSMEs fail to pay their workers on time due to liquidity problems the country is currently facing. MSMEs workers fail to access cash from banks and as a result they fail to meet their daily needs, which have in turn lowered their job satisfaction. The findings consolidated the findings of earlier studies (Nyanga 2018, Spector 1997, Moyo 2012; Zindiye, 2012) which revealed that employee satisfaction is determined by pay, benefits and general working conditions. The ability of the firm to meet its employee's needs depends on its financial position. A company without a good financial standing is not able to meet its employees' obligations. The study further revealed that most MSMEs have cash flow problems, yet cash flow is the life blood of job satisfaction among MSMEs workers. Cash flow is vital to the survival and growth of business because it enables firms to pay their employees competitive salaries and keep them satisfied and motivated. Respondents indicated that one of the problems emanates from delayed processing of salaries and wages due to incompetence of human resource officers. Delay in processing of salaries results in employees getting paid 30 or more days later than the agreed pay date. The method of payment was viewed as inconsistent and inequitable hence it has become a major impediment to employee satisfaction. Furthermore MSMEs do not give employees both mandatory and voluntarily social security benefits such as medical aid, pension funds and others as provided in the National Social Security Authority policies. A smaller group of respondents 
however indicated that some MSME make huge profits and have good liquidity and a growing market share but they do not invest their resources in employee satisfaction because they do not value it. Employers make unilateral decisions on issues that affect employees such as salaries and other conditions of service. There is very little if any form of collective bargaining that takes place in MSMEs. Unitary approach to labour relations is the most popular approach in MSMEs and labour unions are usually not welcome. The use of the unitary approach makes the process of propelling job satisfaction among employees 'bumpy and thorny' in MSMEs.

One of the challenges faced by MSMEs which has a direct impact on job satisfaction is that MSMEs face stiff completion and market acceptance problems. MSMEs, for example those in food and clothing production face stiff competition from established foreign and local manufacturing firms such as Lever brothers Zimbabwe, Delta beverages and others. MSMEs' failure to penetrate the market and grow their market share makes them fail to satisfy their workers because of financial incapacitation. Furthermore workers whose products have failed to penetrate the market also experiences low self-esteem because they will view themselves as incapable and their products as inferior to those produced by well established firms. Emerging manufacturing SMEs are referred to as 'Museyamwa' a denigrating name given to newly established indigenous manufacturing companies. The name 'museyamwa' lowers employees' self-esteem and efficacy which in turn affect employees' satisfaction levels and the quality of the product. Customers have low regard and low appetite for the products manufactured by indigenous companies because they regard the products as of poor quality. This has become a deterrent for the products to have a competitive edge over imported goods and those produced by established firms. The business environment is ultra-competitive to the extent that only those firms with highly satisfied and competent staff will have a competitive advantage.

The other factor that makes job satisfaction objectives for MSMEs difficult if not impossible is the failure by MSMEs to develop requisite physical infrastructure such as good work stations, spacious offices with adequate power supply. The findings concur with earlier researchers (Maseko \& Manyanis 2011, Fu \& Deshpande 2014) investigations which established that employee satisfaction is influenced by employee's working environment and the degree of safety which employees have. It is difficult for most MSMEs to improve their physical infrastructure because business operation costs have risen and continue to rise due to a number of factors of production. The hardest hit areas are MSMEs because they need to import inputs which they use to manufacture their products. Foreign currency is in short supply in Zimbabwe hence most firms resort to getting it from the informal market which is popularly known as the 'black market'. Exchange rate is higher at the informal market which increases production costs and consequently directly and indirectly affects job satisfaction among MSMEs. 
Failure to delegate tasks and properly manage time in MSMEs has made job satisfaction among employees difficult if not impossible. The study revealed that most managers of MSMEs do not delegate tasks to subordinates. Key responsibilities are centralized to a few individuals who are usually members of the family of the major shareholder or the owner of the company. The rest of the employees are left to do routine and monotonous tasks which result in them not liking their work. If delegated, the task will be ambiguous; managers are not ultra-specific when they delegate duties, roles and responsibilities which results in work getting messed up, role conflict, strained relations between the delegator and delegate which result in lowering the employee's job satisfaction. According to Nyanga et al (2012) role ambiguity is one of the key factors that propel low job satisfaction among employees and has the potential of affecting performance and relations between and among workers. There is need for managers to ensure that delegated roles, tasks and responsibilities are clearly defined. Well defined roles create enthusiasm and zeal for job holders to achieve set targets. Low job satisfaction results in high labor turnover and brain drain. Respondents also expressed concern over the lack of opportunities for promotion and growth which they viewed as one of the factors that make employee satisfaction in emerging manufacturing companies difficult. Sexual harassment was also cited as one of the misdemeanors in MSMEs. Sexual harassment done by managers and those who hold positions of influence on female subordinates impedes efforts to promote job satisfaction among MSMEs employees. Managers requests for sexual favors from their subordinates in return for promotion and salary increments. Shortage of labor in MSMEs in Masvingo has created the problem of child labor (Gukurume \& Nyanga 2013). Most MSMEs resorted to child labor so as to fill manpower gaps caused by brain drain and labor turnover.

\section{CONCLUSION AND RECOMMENDATIONS}

Generally the purpose of this study was to establish the difficulties, challenges and impediments of worker satisfaction in MSMEs in Masvingo, the oldest city in Zimbabwe. Four major conclusions were drawn: a) 'the road' to job satisfaction among MSMEs is not smooth, it is marred by a number of challenges which mainly emanate from operating in economically distressed business environment characterized by uncertainty, complexity, volatility and ambiguity. b) Efforts to increase job satisfaction among MSMEs are impeded by poor organizational performance, cash flow challenges, poor financial performance, lack of opportunities for growth and promotion, centralized organizational structures, distressed economic environment, leadership styles, role ambiguity, poor physical infrastructure and interference of owners of MSMEs. c) Low job satisfaction has resulted in a significant number of MSMEs failing to take off, grow or withstand the pressure exerted by the unstable economic, social and 
fast growing technological advancements that characterize the business environment in Zimbabwe. d) Despite job satisfaction challenges MSMEs experience, they constitute the most viable vehicle for selfsustaining industrial economic development in Zimbabwe and beyond. MSMEs have successfully filled the gap left by established manufacturing companies which retrenched some of their operations due to viability challenges. MSMEs play an integral role to the growth of the economy, poverty eradication and employment creation. There is need for MSMEs managers to prioritize job satisfaction because without employee satisfaction, the quality of products suffers, customer satisfaction also suffers and the whole organization is bound to fail. Appropriate strategies and approaches to deal with the problem of employees' negative attitude towards their jobs need to be addressed. For purposes of easing cash flow challenges MSMEs need to properly budget and plan the management of the firm's financial and material resources. Easing liquidity and cash flow problems helps MSMEs to meet their remuneration obligations on time. The study recommends that line and human resource managers for MSMEs are equipped and imparted with job satisfaction knowledge and strategies through training. Managers need to be equipped with contemporary human resource management approaches so as to capacitate them to propel job satisfaction in MSMEs workers during recession. Transparency and consistency in dealing with employee matters, employee involvement and participation in decision making are also crucial to job satisfaction and engagement hence it should be exercised at all levels of management.

\section{LIMITATIONS}

The study was limited to Masvingo urban because of inadequate financial and material resources. Covering a larger geographical area could have increased the generality of the findings of study. Furthermore, the other limitation of the study was that some participants were constrained of time to be interviewed because of their busy work schedules. To mitigate the limitation the researchers was patient with them and interviewed them at the time which was most convenient for them.

\section{REFERENCE}

Akehurst, G., Comeche J.M and Galindo, M.A. (2009). Job Satisfaction and Commitment in the Entrepreneurial SME. Small Business Economics, 32 (3): 277-289.

Bates, A. (2004). Personnel Management, Harare, Mazongororo Printers

Beaver, G., Boss, C. (2002). Recessionary Consequences on Small Business Management and Business Development. The Abandonment Strategy 8(5): 123-141.

\section{- Book with one author:}


Hedrick, J.L. (2009). Effective donor relations. Hoboken, NJ: John Wiley \& Sons

\section{- $\quad$ Book by two authors or more:}

Kotler, P., Keller, K.L., Brady, M., Goodman, M. \& Hansen, T. (2009). Marketing management (1st European ed.). Harlow: Prentice Hall

Chen, L.Y. (2005). Examining the Effect of Organization Culture and Leadership Behavior on Organizational Performance. International Journal of Business and Management 8 (13): 1-9.

Chen, J.C., Silverthorne, P. (2008). The Impact of Locus of Control on Job Stress, Job Performance and Job Satisfaction in Taiwan. Leadership and Organization Development Journal 29 (7), P. 572-582.

Fu, W and Deshpande, S.P. (2014). The Impact of Caring Climate, Job Satisfaction, and Organizational Commitment on Job Performance of Employees in China's Insurance Company. Journal of Business Ethics 24(2): 339-349.

Gombarume, F.B., Mavhundutse, S. (2014).Challenges Faced by Small to Medium Scale Enterprises: A Case Study of Chitungwiza, Zimbabwe. Journal of Business and Management Studies. 4(4): 103-107. Gukurume, S., Nyanga, T. (2013). Reconciling Work and School: A Case Study of Working Children in Mucheke Suburbs in Masvingo, Zimbabwe. Journal of Sustainable Development in Africa 13 (3): 1-19. Manzoor F , Wei L, Nurunnabi M, Subhan O.A , Ali Shah S.I., and Fallatah S., (2019). The Impact of Transformational Leadership on Job Performance and CSR as Mediator in SMEs, Sustainability 11: 436-451.

Maseko, B., Manaynisi ,C.K. (2011). Review of Job Satisfaction Theories. International Journal of Human Resource Management 8 (1): 57-69.

Milenkovic, M. (2019). Job Satisfaction Statistics: Keep Your Workers Happy and Your Business Healthy. IPMZ 12: 1-18.

Moha, A.A, Munir, S,Zikri, M,Hassan N, Norizan .M, and Junaimah, J. (2007). Employees Organizational commitment in SMEs: Evidence from the Manufacturing Sector in Malaysia, International Review of Business Research 3 (2): 12-26.

Moyo, S.P. (2012). Employee Engagement, involvement and Motivation: A Case of Farm Workers in Lilongwe, Business Review 3 (1): 98-109.

Nyanga, T. (2018). Examining the Usefulness of Job Satisfaction Theories in Armed Conflict Society. Amity Global Human Resource Management Review 8 (2), 40-48.

Nyanga, T., Mudhovozi, P., and Chireshe, R. (2012). A Survey of Job Satisfaction of Employees at Higher Learning Institutions in Masvingo Province, Zimbabwe. Anthropologist 14 (1), 73-79. 
Nyanga, T., Sibanda, R. (2015). Complexity of Organisational Conflict: An Exploration of Implications on Sustainable Growth in the Hospitality Industry in Zimbabwe. Journal of Emerging Trends in Economics and Management Sciences 6 (3), 202-208.

Nyanga, T., Sibanda, R. (2019). The Magnet that Truss Domestic Workers and Employers in Armed Conflict Societies: A Case of Mazoe in Changara District in Mozambique. Vietnam Social Sciences Review 4, 22-36.

Nyanga, T., Sibanda, R., Kruger, J. (2018). Financial Growth and Stability in Armed Conflict Society: Does Job Satisfaction Play a Role?, Amity Journal of Management Research 3 (1), 1-13.

Nyanga, T. Mudhovozi, P., Chireshe, R. (2013). Causes and Effects of Role Ambiguity as Perceived by Human Resource Management Professionals in Zimbabwe, Journal of Social Sciences 30 (3): 293-303. SEDCO, 2010. Report, SEDCO, Harare.

Shamuni, K., Kunjiapu, A., Ruhizan, M. (2015). Skill Development and Job Satisfaction through Workplace Learning in Small and Medium Tourism Enterprises in Malaysian, Journal of Chinese Studies 4(1): 15-29.

Spector, P. (1997). Job satisfaction, London, Sage Publications.

Sugandini, D., Mustafa El Qadri, Z., Kustyadji, G. (2018). Employee Engagement in Entrepreneurship Management: SMEs Cases. Academy of Entrepreneurship Journal 24(2): 1-12.

Tinarwo, R. (2016). An investigation into the Challenges Faced by Small to Medium Enterprises in Zimbabwe: A Case of Gazaland Market. Journal of Business and Management 18 (9): 423-439.

Zindiye, S. (2012). An Empirical Investigation into the Factors Affecting the Performance of Small and Medium Enterprises in the Manufacturing Sector of Harare, Zimbabwe. Journal of Business Development 19 (17): 12-29. 